\title{
COMPUTATIONAL THINKING, PROGRAMMING AND ROBOTICS IN BASIC EDUCATION: EVALUATION OF AN IN-SERVICE TEACHER'S TRAINING B-LEARNING EXPERIENCE
}

\author{
Lúcia Amante ${ }^{1}$, Elizabeth Batista de Souza ${ }^{1}$, António Quintas-Mendes ${ }^{1}$, \\ A.F. Monteiro ${ }^{2}$, M. Miranda-Pinto ${ }^{3}$, A. Osório², C.L. Araújo ${ }^{4}$ \\ ${ }^{1}$ Le@d - Universidade Aberta (PORTUGAL) \\ ${ }^{2}$ Research Centre on Education (CIEd), University of Minho (PORTUGAL) \\ ${ }^{3}$ ESEViseu - School of Education; Research Centre on Education (CIEd), University of Minho \\ (PORTUGAL) \\ ${ }^{4}$ Research Centre on Education (CIEd), University of Minho; ISCTE-University Institute of \\ Lisbon, CIS (PORTUGAL)
}

\begin{abstract}
This paper presents a training program for teachers and the procedures for its evaluation in the domain of computational thinking, programming and robotics in basic education. This training was conducted within the scope of Project KML II - Laboratory of programming and robotics technologies and learning for preschool and primary school (1st CEB) and is expected to contribute for two of the project's main outcomes: conceive a training plan to include in the higher education of educators and teachers of the 1st ECB and the creation of a MOOC for initial and continuous training of these professionals. The training, with 50 hours of total workload, was developed in a blended learning format, including face-to-face and online sessions (25 hours each). The online sessions were organized into synchronous and asynchronous activities, including autonomous working moments, to perform individual activities. The theoretical references that support this work have their origins in the studies on distance education (EaD), namely in the developments provided by the designated 3rd generation of EaD in which computer-mediated communication has allowed the emergence of new pedagogical scenarios giving rise to new training modalities either fully online or in blended learning format. The training evaluation questionnaire aims to explore the key points that determined the organization of the course and aims to evaluate the level of satisfaction and the opinion of the trainees about the different components of the training, as well as gather information that may contribute to the design of new course in a MOOC format. The questionnaire was designed considering the following dimensions: characterization of respondents and previous experience, satisfaction with training, perception of the learning and involvement in training, perception of the practical application of training, criticism and suggestions for improvement. The questionnaire, in the context of this research, will be an essential source of information for the team's decision-making on the appropriate format for the MOOC to be developed in the future and which constitutes one of the project's final objectives with a view to broadening the access of teachers in Portugal to knowledge on the subject under study.
\end{abstract}

Keywords: Computational thinking, programming and robotics, teacher education, Blended Learning; Virtual learning environment.

\section{INTRODUCTION}

In today's technology saturated society, communication, learning and participation are increasingly mediated by computers. In this context, understanding how computers work and the 'languages' with which they change, or setup, the social contexts we live in becomes an agency issue. Beyond technical skills, learning these new languages serves communicative and expressive functions, hence addressing inclusion and participation challenges of today's digital society [1]-[3]. In short, together with economy-related concerns, notably the presumed need for a tech-savvy future workforce, this is the motivation beneath the exponential attention given to computer science by educational policies and practices [4], namely in Portugal [5]-[8].

In this context, "KML II - Laboratory of technologies and learning of programming and robotics for preschool and primary school" arises from the need to empower teachers to make the best use of programming and robotics as learning means. Its' aim is to study how to integrate programming and robotics in preschool and basic education [9]. Within this project, case studies will be carried out at a 
national level with two main objectives: a) to propose a training framework for curricular units of technology, in the courses for teacher training in higher education and in-service training; b) to design a profile of childhood educator and elementary school teacher as mediator in the integration of programming and robotics learning in educational contexts. The project further expects to survey training needs in technology, programming and robotics of elementary school teachers and early childhood educators; contribute to a framework for the integration of programming and robotics in the curriculum.

The KML II project encompasses the creation of laboratories in higher education institutions, for the learning of programming and robotics by students of initial, postgraduate and continuing education. It further includes a mobile lab for schools participating in the project. Thus, it intends to distribute at a national level the resources provided by the project. Partners involved will also be consultants in the development of the framework [9].

\section{THE DESIGN OF ONLINE COURSES IN VIRTUAL LEARNING ENVIRONMENTS}

The new learning scenarios that have emerged under the so-called 3rd generation of Distance Education [10], [11] have made it possible for trainers and designers to implement courses based on computer-mediated communication to devise new pedagogical approaches, use the technological resources that can best support these approaches, as well as identify strategies that can enhance learning processes in these new contexts, depending on the nature of the topic being addressed, the characteristics of the target audience and the specific circumstances surrounding the processes of training. Thus, from the outset, trainers and designers have the option of adopting a training plan that uses online communication for developing courses totally at a distance or alternatively using online communication for combining it with face-to-face sessions in blended learning courses. We will try to present a brief reflection on the basic aspects that surround this option.

\subsection{Computer Mediated Communication and Blended Learning}

Considering the nature of the modality of the training course described in this paper, it is important to consider the concept of Blended Learning. In its strongest sense "blended learning" involves combining sessions of face-to-face interaction with forms of online interaction [12].

Problems and weaknesses are often pointed to online communication in teaching and learning contexts due to its alleged limitation in what concerns human interaction and lack of social contact for one side and due to limitations in certain fields of knowledge that would require visualization processes, physical contact or direct manipulation of elements of the real [13], [14]. On the other hand, it has been signaled one great advantage of online communication, namely that it allows access to training to geographically dispersed populations as well as the temporal flexibility that allows particular audiences to overcome temporal limitations due to incompatible working hours or family time.

The first type of signaled disadvantage has been largely contested by both practice and empirical research. Online learning communities, enjoying the benefits of networked communication and fueled by collaborative learning principles, benefit from the strong social-affective, cognitive and motivational components of the Web [10]. Difficulties in remotely promoting the acquisition of certain skills, in certain areas requiring real physical contact with people or with instrumentation and procedures, are a relevant argument when arguing against online education but those problems are also likely to be overcome. Indeed, these difficulties have generated innovations in the field of simulations, virtual laboratories and remote control laboratories, artificial intelligence, virtual collaboration, vizualization and gamification, which areas of great interest to distance education and online education [15].

The underlying reason for the emergence of mixed education is undoubtedly the idea that such a teaching modality can collect, in an eclectic way, the advantages of face-to-face interaction and the advantages of mediated education, namely of computer mediated communication. In short, a blended learning solution will be all the better if it can benefit from the strengths of each of the teaching modalities without incorporating the weaknesses of either one [16].

The design of mixed courses implies the search for balances between the amount of face-to-face and online interaction and the nature of the instruction intended to be provided in each of these modalities. It is therefore necessary to make options according to the instructional objectives, fields of study, the characteristics of the students, their geographical distribution, the available online resources or the 
available physical spaces and the existence of teachers or tutors with adequate skills for the desired training.

Therefore, the different ways of conceiving mixed courses are not indifferent to the starting points and the contexts in which the courses are implemented. In this sense, the blended learning proposal presented here took into account:

- The nature of the training to be developed: some activities, such as robotics initiation, involve the assembly and manipulation of robots, and so there is advantages in being developed in face-to-face situations, providing greater security for participants and easier collaboration between trainees and between trainees and trainers. Given that this is a completely new area for many educators, we believe this option has attracted more participants

- The target audience: we were dealing with an adult audience, geographically dispersed and for whom the principles of temporal and spatial flexibility, characterizing online communication and distance education, assume significative importance.

- The network of trainers and training spaces: there was a network of local trainers qualified in the area and available to ensure these moments of face-to-face training. They were also very knowledgeable about the specific contexts of the target audience.

- The possibility of having a Virtual Learning Environment (VLE) that could integrate the entire training course, allowing autonomous work activities, making resources available, and virtually extending the moments of presential learning, enhancing the interaction between all involved.

Thus, our option was to present the entire training plan in the Virtual Learning Environment (VLE), although this training plan included both the virtual activities and interactions and face-to-face sessions in various parts of the country, with support. of trainers on the ground that worked in accordance with the general directions set by the training plan design team.

\subsection{Interaction and Interactivity}

In the field of Online Education there have been several theories developed over the years such as Michael Moore's Transactional Distance Theory [17] Garisson, Anderson and Archer Community of Inquiry Model [11] or Siemmens Connectivism [18]. However, rarely are these theoretical models explicitly seen as design tools that can directly serve to design and implement online courses, thus falling within a logic of descriptive / interpretive theories rather than in a logico of a learning design model which is, in the context of the present work, what we value most.

As we know, interaction is one of the most important components of any learning experience and is certainly also one of the most important constructs in research in Distance and Online Education [19] [21]. In this sense, and because it was also one of the main concerns of the project team in the course design and the design of its Virtual Learning Environment (VLE), we will highlight in this paper this component in particular.

In the field of Distance Education, Moore [19], [22] introduced of "transactional distance" and distinguished between three types of interaction: student-teacher, student- content, and studentstudent. According to Moore, the physical non-presence of the subjects generates a particular space of interaction, that of transactional distance. Moore considers that transactional distance is a phenomenon of psychological, communicational and pedagogical nature and not so much of spatial or geographical nature.

Student-Content interaction is one of the fundamental types of interaction on which all education is based. Content is found in books, environmental objects, videos, digital artifacts, etc. Student-Teacher interaction can take the form of direct instruction through lessons and lectures or through dialogue, feedback and student incentives. In addition, students can interact with the teacher by asking questions, presenting assignments, or discussing problems. The student is able to learn from the teacher's experience and knowledge, and the teacher is able to gauge and assess student needs.

Student-Student interaction constitutes today a huge challenge for thought and educational practice. Students collaborate with colleagues on projects, assignments, discussions, exchange ideas and interact on various topics in a more or less formal / informal way. Student-Student interaction may occur with or without the presence or influence of the teacher. Its value to Moore largely depends on the students' circumstances and their age, experience and level of autonomy. The possibility of Virtual Learning Environments to provide and even foster this type of interaction is an important point to underline. 
In Distance Education and Online Education all interaction is mediated through a technological medium. For any of the above three types of interaction to occur, the student has to interact with the media, and Hillman, Willis, and Gunawardena [23] have proposed a fourth type of interaction: StudentInterface interaction. These authors identified the interfaces of technological environments as points of interaction between the content, the students, and the teacher. Successful learning requires students and teachers to be comfortable with these interfaces [23].

These four different types of interaction guided the team's work in the development of the VLE, its design, definition of the resources to be used and the organization and planning of the training package.

\section{THE TRAINING PROGRAM}

The Training "Computational Thinking, Programming and Robotics in Basic Education" was held between June and October 2019, lasting 50 hours, in b-learning format (25 hours of face-to-face classroom activities and 25 hours of distance activities). 120 teachers participated in the training, distributed in eight classes, representing 8 regions of Portugal.

The training curriculum was organized in a total of 11 learning sessions (five in-person and six at a distance), divided into three modules (Computational Thinking, Educational Robotics and Programming) and included two sessions for the preparation of a project and a final report. .

The materials, resources and evaluation activities foreseen in the training to stimulate the students' interaction with the contents, as well as between themselves and the trainers, were made available in the VLE, instantied in the platform Moodle.

The face-to-face sessions were held at each regional hub and coordinated by expert trainers from each of the partner institutions participating in the project. The presential moments were intended for group activities, the discussion of the specific themes of each module and, in particular, the manipulation of the equipment, namely in the Educational Robotics module, when it was possible to handle the various devices provided by the team project.

The online activities contemplated synchronous and asynchronous moments. The synchronous moments were held in videoconferencing format and had as main objective the introduction of new themes, through expert lectures, detailed explanation of the autonomous activities and clarification of doubts, as they enabled interaction with the speaker in real time. These synchronous moments occurred simultaneously with trainees and trainers from all classes and were always recorded, giving everyone the opportunity to review these sessions. For trainees who did not attend for some reason, they were able to attend later, and could leave their comments in the module forum under consideration, so that their participation could be recorded. Asynchronous communication took place in the VLE, primarily through the thematic discussion forums and doubt forums, which constituted spaces complementary spaces related to the discussions that began in the face-to-face sessions.

In the virtual learning environment were also defined the assessment and evaluative activities of the training, all individually performed, including the project and the final report, developed by the trainees in autonomous working hours. In addition to the resources, forums and evaluative activities, it should be noted that in the VLE the students had access to guiding training documents: The General Training Guide that presented essential information, such as objectives, methodology, schedule, topics for study, systematic evaluation of learning and criteria for training certification; and the Session Guides, detailed documents on the work to be done in each of the training sessions, be it in person or at a distance.

\section{TRAINING ASSESSMENT}

At the end of the training a questionnaire will be applied to assess the satisfaction of the trainees and collect information that may support the project team in the design of a similar course but in a MOOC format. The anonymous questionnaire will be applied at the last session and will be made available in digital format (Google docs). The following are the dimensions that guided the construction of the Training assessment instrument.

\subsection{The Training Assessment Questionnaire}

From the objectives aimed, five dimensions were defined to guide the elaboration of the questions, namely: characterization of the respondents and previous experience, satisfaction with the training, 
perceptions about the learning and involvement in the training, perceptions about the practical application of the training and criticisms and suggestions for improvement of the training program.

The first dimension, which includes eight questions, sought to collect some demographic data from the respondents considering variables such as age, gender, education level that teaching, etc. In addition, it brought questions that ascertained the experience of the trainees in distance learning courses and in the specific theme of training.

The second dimension "satisfaction with training" encompasses thirteen questions that seek to highlight the reaction of the trainees to the training program as a whole, from the training environments to the pedagogical strategies, the performance of the trainers, the materials and didactic resources, among others. A special attention was given to the format of training (b-learning), which sometimes required context-specific questions.

The third dimension "perception of learning and involvement in training" relates to how much learners consider they have learned from the training experience. For this, we sought to elaborate three questions that would lead them to reflect on the level of learning achieved in each theme addressed, that is, allowing them to perform a self-assessment of their training path.

The fourth dimension "perceptions about the practical application of training" concerns the anticipation that learners make about the possible transfer of knowledge, skills and attitudes acquired in training to their everyday pedagogical practice. This dimension was evaluated by two questions, one of which involves three items. Consideration was given not only to teachers' individual intention and motivation to introduce new knowledge, skills and attitudes into their work routine, but also to the real possibility of such transfer, based on the infrastructures available in their classrooms.

"Criticism and suggestions for improvement" was the fifth and final dimension defined in the questionnaire and considers four open questions. It seeks to involve learners in the process of improving training by presenting them questions in which they are invited to point out the weaknesses and strengths observed and, above all, to indicate improvements for possible future editions of the course. This dimension also included more specific questions about the virtual learning environment and the dynamics established on the online sessions, considering the relevance of this information for the MOOC design and production process to be developed.

Regarding the type of questionnaire, we occasionally considered the multiple choice format, but most questions take the form of statements against which respondents should indicate their degree of satisfaction / dissatisfaction, or degree of agreement / disagreement, or express your opinion / attitude. This is why we used a five-level Likert scale where each extreme indicates semantically opposite positions, "Strongly Agree / Strongly Disagree; Very Satisfied / Very Dissatisfied ", etc. This method allows obtaining complex and subjective information, such as perceptions, attitudes, representations, preferences and opinions [24].

The matrix in table 1 seeks to account for the structure and nature of the questionnaire in each of its dimensions.

Table 1: Matrix of the questions from the questionnaire by dimensions

\begin{tabular}{|c|c|c|}
\hline Dimensions & Questions Topics & Scales \\
\hline \multirow{8}{*}{$\begin{array}{c}1- \\
\text { Characterization } \\
\text { of the subject } \\
\text { and their } \\
\text { previous } \\
\text { experience }\end{array}$} & 1- Gender & - Dichotomic \\
\hline & 2- Age & \multirow{7}{*}{$\begin{array}{l}\text { Example of question } \\
\text { Education: } \\
\begin{array}{l}\text { a. Graduation } \\
\text { b. Masters degree } \\
\text { c. PhD } \\
\text { d. Other }\end{array}\end{array}$} \\
\hline & 3- Education & \\
\hline & 4- Region & \\
\hline & 5- Level of education that teaches & \\
\hline & $\begin{array}{l}\text { 6- Previous distance education } \\
\text { experience }\end{array}$ & \\
\hline & $\begin{array}{l}\text { 7- Previous experience in the } \\
\text { topics of the present training. }\end{array}$ & \\
\hline & $\begin{array}{l}\text { 8- Previous experience with } \\
\text { robotics in the classroom. }\end{array}$ & \\
\hline
\end{tabular}




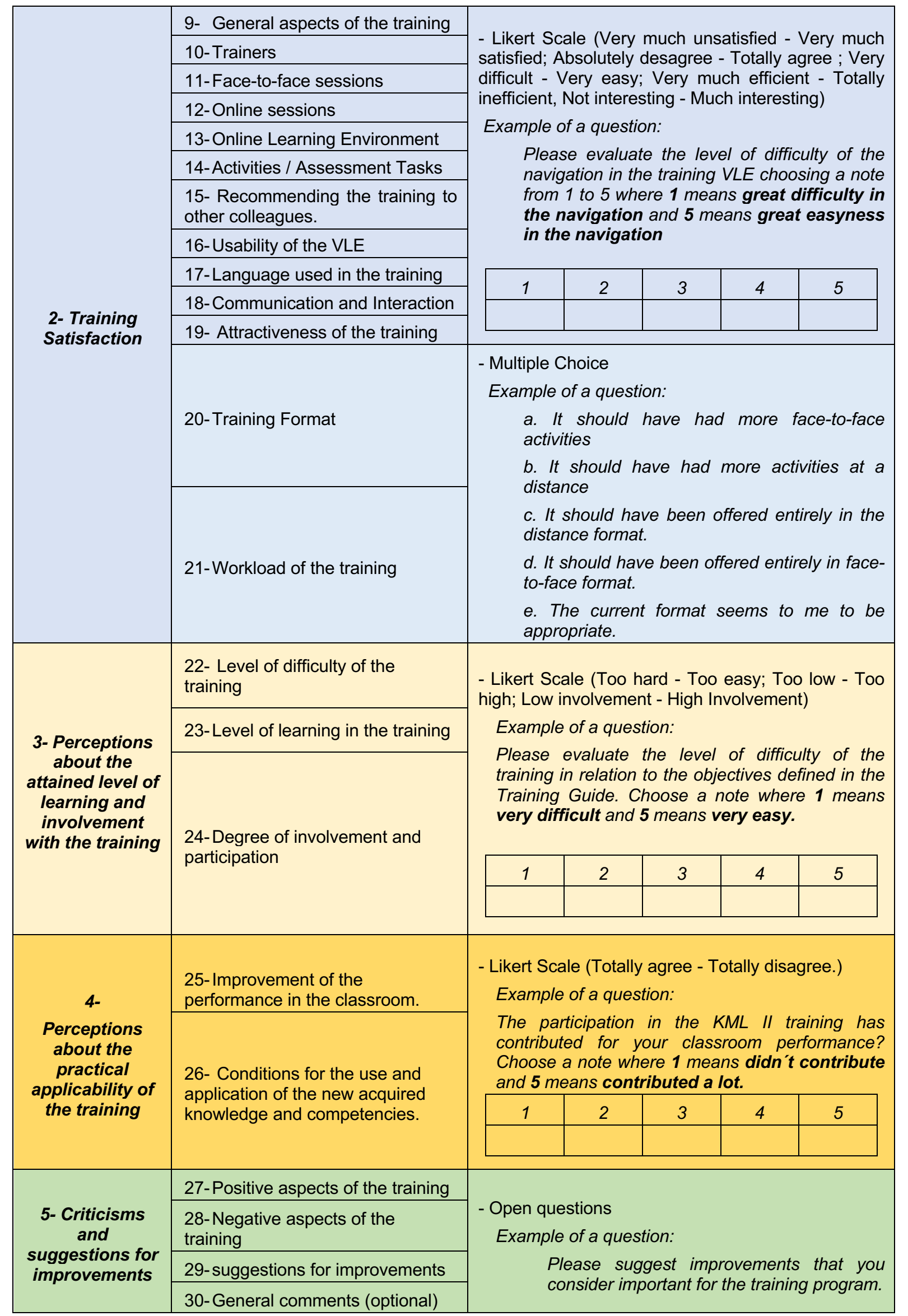

Source: Elaborated by the authors 


\section{FINAL CONSIDERATIONS}

The questionnaire whose construction logic was detailed here has already been validated by a set of five experts on the project team. This validation process gave rise to changes that improved the instrument. However, it is still intended to submit it, prior to its application to the target audience, to a small sample of teachers in order to collect their input and suggestions. It will then be applied to trainees at the beginning of October 2019 at the last in-person training session.

The results obtained should allow the project team to collect indicators on the training profile that best suits the target audience, contributing to the planning and construction of a MOOC, which aims to broaden the scope of the training undertaken, with a view to encompass a wide range of teachers from the Portuguese education network. This network currently includes 16,065 educators and 29,979 teachers of the 1st cycle of basic education, according to data from 2019 from Pordata.pt. [25]

Within these indicators, it is emphasized the importance of the evaluation made by the trainees along the various dimensions of the questionnaire, regarding the aspects / items related to the interaction / interactivity component, considering both the three types of interaction proposed by Moore [12] (student - content). ; student - teacher; student - student) and the student / interface interaction proposed by Hillman, Willis and Gunawardena [16]. As this component is crucial for learning, it is important to draw from this training experience substantive data on learners' opinions and the relevance they attach to these different interactions. This will be one of the main focuses of the interpretation of results that we propose to do.

\section{ACKNOWLEDGEMENTS}

Project KML II is co-financed by FEDER through the COMPETE 2020 - Operational Thematic Program for Competitiveness and Internationalization (POCl) and national funds through FCT Portuguese Foundation for Science and Technology under project reference number PTDC/CEDEDG/28710/2017.

\section{REFERENCES}

[1] M. U. Bers, "Coding as another language: a pedagogical approach for teaching computer science in early childhood," J. Comput. Educ., pp. 1-30, Sep. 2019.

[2] M. U. Bers, Coding as a playground : programming and computational thinking in the early childhood classroom. New York: Routledge, 2018.

[3] S. Popat and L. Starkey, "Learning to code or coding to learn? A systematic review," Comput. Educ., vol. 128, pp. 365-376, Jan. 2019.

[4] Stefania Bocconi, Augusto Chioccariello, Giuliana Dettori, Anusca Ferrari, and Katja Engelhardt, "Developing Computational Thinking in Compulsory Education - Implications for policy and practice | EU Science Hub," Brussels, 2016.

[5] J. L. P. Ramos and R. G. Espadeiro, "Iniciação à Programação no 1.o Ciclo do Ensino Básico Estudos de Avaliação do projeto-piloto," Lisboa, 2016.

[6] Direção Geral da Educação, "Iniciação à Programação no 1.o Ciclo do Ensino Básico: Linhas orientadoras," Lisboa, 2015.

[7] M. dos S. Miranda-Pinto, "Desafíos de programación y robótica en Educadión Preescolar: proyecto Kids Media Lab," Tecnol. innovación e Investig. en los procesos enseñanza-aprendizaje, 2016, ISBN 978-84-9921-848-9, págs. 1848-1855, pp. 1848-1855, 2016.

[8] M. S. M. Pinto and A. Osório, "Aprender a programar en Educación Infantil: análisis con la escala de participación," Píxel-Bit. Rev. Medios y Educ., vol. 0, no. 55, pp. 133-156, Apr. 2019.

[9] M. dos S. Miranda-Pinto et al., "Laboratory of technologies and learning of programming and robotics for pre and primary school," ICERI Proc., pp. 1497-1502, 2017.

[10] L. Harasim, "Shift happens: Online education as a new paradigm in learning". The Internet and Higher Education, 3, pp. 41-61,2000. Retrieved from https://www.researchgate.net/publication/223257621_Shift_Happens_Online_Education_as_a_N ew_Paradigm_in_Learning 
[11] D.R. Garrison, T. Anderson and W. Archer, "Critical inquiry in a text-based environment: Computer conferencing in higher education model". The Internet and Higher Education. V. 2(2-3), pp. 87-105, 2000. Retrieved from https://www.researchgate.net/publication/222474115_Critical_Inquiry_in_a_TextBased_Environment_Computer_Conferencing_in_Higher_Education

[12] D. Laurillard, "Thinking about blended learning. Thinkers in Residence programme". Royal Flemish Academy of Belgium for Science and the Arts (KVAB). UCL Institute of Education, London, 2014. Retrieved from http://www.ethicalforum.be/sites/default/files/DP_BlendedLearning_Thinking-about_0.pdf

[13] R. E. Kraut, S. R. Fussell and J. Siegel, "Visual information as a conversational resource in collaborative physical tasks". Human Computer Interaction, vol. 18, pp. 13-49, 2003.

[14] D. Gergle, D. Millen, R. Kraut and S. Fussell, "Persistence matters: Making the most of chat in tightly-coupled work". Proceedings of the Conference on Human Factors in Computing Systems (CHI), pp. 431-438, 2004.

[15] D. P. Nickerson et al, "Did2 coordinates Vps4-mediated dissociation of ESCRT-III from endosomes". J Cell Biol, 175(5):715-20, 2006.

[16] R. T. Osguthorpe and C. R. Graham, "Blended Learning Environments: Definitions and Directions". The Quarterly Review of Distance Education, vol. 4, pp. 227-233, 2003.

[17] M. Moore, "Theory of transactional distance". In D. Keegan (Ed.) Theoretical principles of distance education. New York: Routledge,1993.

[18] G. Siemens, "Connectivism: A Learning Theory for the Digital Age". Elearnspace, 2004.

[19] Moore, M. - Editorial: Three types of interaction. The American Journal of Distance Education. Vol. 3(2), pp. 1-7, 1989.

[20] J. Dron, "Control and Constraint in E-Learning: Choosing When to Choose". Hershey: Idea Group Publishing, 2007.

[21] J Dron and T. Anderson, "Teaching Crowds - Learning and Social Media". Edmonton: AU Press, 2014.

[22] M. Moore, "Editorial: Distance Learning Theory". The American Journal of Distance Learning, vol. 5, pp. 1-6, 1991.

[23] D.C. Hillman, D. J. Willis and C. N. Gunawardena, "Learner-interface interaction in distance education: An extension of contemporary models and strategies for practitioners". The American Journal of Distance Education, vol. 8(2), pp. 30-42, 1994.

[24] L. Cohen, L. Manion and K. Morrison, "Research Methods in Education" (6th ed.). NY Routledge Falmer, London and New York, 2007.

[25] Pordata. Base de Dados Portugal Contemporâneo. Acessed 26 september, 2019. Retrivied from https://www.pordata.pt/DB/Portugal/Ambiente+de+Consulta/Tabela 